\title{
Acessibilidade e aglomerações na \\ Região Norte do Brasil sob o enfoque da \\ Nova Geografia Econômica
}

\section{Palavras-chave}

Amazônia, acessibilidade, geografia econômica, desenvolvimento regional, modelos espaciais.

\section{Classificação JEL}

R11, C31, R58.

\section{Keywords}

Amazon region, accessibility, regional development, economic geography, spatial models.

\section{JEL Classification}

R11, C31, R58.

\section{Resumo}

O objetivo deste artigo é quantificar e analisar os determinantes do crescimento populacional desigual dos municípios da Região Norte do Brasil, de 1980 a 2000, fundamentado na Nova Geografia Econômica (NGE). Utiliza-se como variável explicativa um índice de potencial de mercado desenvolvido para a Amazônia, o qual substitui a equação dos salários da NGE. As equações são estimadas aplicando o método de econometria espacial. Constatou-se que os municípios mais pobres da Região Norte têm no fator isolamento geográfico um dos determinantes da sua condição econômica. As dificuldades de acesso impedem esses municípios de escoar sua produção, basicamente oriunda da agropecuária, aos mercados potenciais. Confirmou-se também que houve redução nos custos de transportes, que culminou na melhoria da acessibilidade e na formação das aglomerações populacionais.
Renilson Rodrigues da Silva*

Carlos José Caetano Bacha**

\section{Abstract}

Based on the New Economic Geography (NEG), this paper aims to quantify and analyze the determinants of the unequal growth population of municipalities in the Northern Region of Brazil from 1980 to 2000 . Together with first and second-order explanatory variables, a market potential index was also used to explain urban and rural population growth. The equations were run by using spatial econometric techniques and it was found that the poorest municipalities have the geographical isolation as one of the main determinant of their population growth. The access bottlenecks prevent these municipalities of transporting their production - mainly from agriculture - to the potential market. It was found that the transportation cost has decreased due to the improvement of accessibility, and consequently creating the agglomerations. The paper ends with some suggestions of policies that would reduce the unequal growth of population in the Northern Region. 


\section{1_Introdução}

A Região Norte do Brasil é marcada pelas suas peculiaridades, entre as quais se incluem a acentuada desigualdade socioeconômica e também o isolamento geográfico em relação às regiões mais desenvolvidas do país. Seus indicadores sociais estão entre os piores do Brasil,em contraste com o seu expressivo crescimento econômico e populacional, muito acima da média nacional. $\mathrm{O}$ meio de transporte comumente utilizado é o fluvial, e o tempo de viagem de um município a outro pode superar 15 dias, deixando muitas cidades isoladas geograficamente, e nas quais se observam altos índices de pobreza. Compreender a dinâmica populacional dessa região, no âmbito das aglomerações populacionais, é o propósito deste trabalho. Para tanto, aplicam-se os preceitos da Nova Geografia Econômica (NGE) e utiliza-se, como uma das variáveis explanatórias, a acessibilidade, a qual capta os efeitos de potencial de mercado e a infraestrutura de transporte. ${ }^{1}$

Entre os anos 1950 e 2000, a população da Região Norte cresceu $1.570 \%$, ao passo que a nacional, $709 \%$. O Produto Interno Bruto (PIB) regional cresceu 338,6\%, e o nacional, $140,4 \%$. No entanto, esse crescimento foi desigual dentro da Região Norte. A população urbana corresponde a aproximadamente $70 \%$ do total e continua crescendo, enquanto a população rural é decrescente. É importante ressaltar que o período analisado neste artigo incorpora os efeitos da forte onda migratória de fins dos anos 1970, que se consolidou na década de 1980 e perdeu força na década de 1990, quando a infraestrutura de transporte naquela região já não apresentava mudanças substanciais.

Conforme destacam Prates e Bacha (2011), nesse período a presença humana na Amazônia foi garantida por meio dos projetos de colonização, medidas fiscais e creditícias. Um desses projetos, o Polamazonia, culminou com a migração de pessoas com maior poder econômico, a qual resultou na expansão das empresas agropecuárias e de mineração na Região Norte. Novos migrantes foram atraídos com o crescimento da agropecuária e da mineração. Contudo, a concentração fundiária e o intenso uso do capital na mineração resultaram em novo processo migratório interno, dessa vez, das zonas rurais para as zonas urbanas, caracterizando a região tal como ela está nos dias atuais.

A migração intrarregional para as zonas urbanas resultou também na concentração de renda. Em 2006, no Estado do Amazonas, por exemplo, a capital Manaus detinha 51\% da população e 81,5\% do PIB. Em Roraima, a capital Boa Vista detinha $61,9 \%$ da população e $71 \%$ do PIB. No Amapá, 59,8\% da população estava na capital, que concentrava $64 \%$ do PIB. No Acre, a capital Rio Branco concentrava $46 \%$ da população e $54 \%$ do PIB. O Estado com a população e riqueza mais equilibrada era, em 2006, Tocantins, onde a capital Palmas concentrava $16,6 \%$ da população e $20 \%$ do PIB. Entretanto, se considerados os cinco maiores municípios, essa concentração subia para 38,5\% e 47\%, respectivamente (IBGE, 2009). Além das capitais, há cidades com população atual acima de 100 mil habitantes, que possivelmente impulsionam o crescimento econômico das regiões vizinhas. Esses centros são: Ji-Paraná, em Rondônia; Parintins, no Amazonas; Santarém e Marabá, no Pará; Santana, no Amapá; e Araguaína, no Tocantins.

As transformações ocorridas na Região Norte, de 1980 a 2000, não foram acompanhadas por níveis de qualidade de vida satisfatórios para a maioria de seus habitantes. Em 2000, por exemplo, o segundo pior Índice de Desenvolvimento Humano (IDH) do Brasil pertencia ao município de Jordão, no Estado do Acre. Não por acaso, esse é um dos municípios mais isolados do Brasil. O seu IDH em relação à média nacional foi de $38 \%$ e, em relação ao melhor IDH da Região Norte, ${ }^{2}$ foi de $41 \%$ em 2000. Por outro lado, o melhor 
IDH municipal na Região Norte em 2000 foi 5,2\% superior à média nacional. Da mesma forma, a preservação da floresta ficou na contramão do crescimento. Além de índices sociais díspares, o nível de degradação ambiental foi igualmente expressivo, com grandes áreas desmatadas nas proximidades das rodovias construídas nas décadas passadas, equivalente ao tamanho de países como a Bélgica, por exemplo (Da Silva, 2009).

Constata-se, portanto, que o crescimento econômico e populacional da Região Norte não tem ocorrido de forma equilibrada e sustentável. Isso pode ser atribuído, em parte, à falta de acesso de boa parte de sua população a serviços de saneamento básico e educação, por exemplo. Apesar disso, há também outras variáveis que influenciam esses resultados. Entre elas, está o acesso às cidades com melhor infraestrutura, que, na maior parte da região, é limitado ao modal fluvial. A carência de infraestrutura de transporte é uma constante para quase todos os Estados da Região Norte, onde existem várias cidades quase que completamente isoladas, cujas populações crescem pouco ou mesmo decrescem.

Para avaliar a dinâmica de crescimento acima aludida, é necessário: (1) evidenciar como o sistema de transporte afeta essa dinâmica; (2) discutir como políticas públicas podem ser elaboradas para permitir a redução das desigualdades regionais; e, (3) devem-se considerar os impactos que os investimentos em infraestrutura de transporte ocasionaram na região em questão. No contexto do desenvolvimento territorial, a infraestrutura de transporte determina a qualidade de uma localização em relação a outras; ou seja, ela indica a vantagem competitiva dos locais, geralmente medida como acessibilidade. Portanto, faz-se necessário o uso de uma variável que capte os efeitos descritos acima. Isso é feito por meio do Índice de Acessibilidade. Nesse sentido, será possível determinar em que nível a dinâmica populacional ocorrida nas últimas décadas foi ocasionada pelas mudanças no nível de acessibilidade.

Maior acessibilidade a serviços de alto valor adicionado e acesso a grandes mercados potenciais têm favorecido o deslocamento e a fragmentação das atividades produtivas. Isso leva ao deslocamento da população em busca de oportunidades nos grandes centros econômicos. Assim, pode ser que o forte crescimento - populacional e econômico - de algumas cidades da Região Norte esteja respondendo a um novo modelo de organização socioterritorial. Esses aspectos podem ser mais bem compreendidos se examinados à luz das construções teóricas e analíticas da Nova Geografia Econômica (NGE).

A fim de esclarecer as questões acima, o objetivo deste trabalho é analisar o crescimento populacional desigual dos municípios que compõem a Região Norte do Brasil e quantificar seus determinantes no período de 1980 a 2000 usando os conceitos da Nova Geografia Econômica. Para tanto, evidenciar-se-á o crescimento dos municípios associando-o com as condições naturais da região. Utilizam-se as variáveis demográficas (obtidas no censo demográfico) e um Índice de Acessibilidade. O período escolhido para análise, de 1980 a 2000, cobre a fase em que os projetos de infraestrutura implantados na década de 1970 surtiram seus principais efeitos, em particular, nas mudanças da acessibilidade.

As hipóteses formuladas neste trabalho são: $1^{0}$ ) os municípios mais pobres têm no fator isolamento geográfico um dos determinantes da sua condição econômica e de seu crescimento populacional. As dificuldades de acesso os impedem de escoar sua produção, que na maioria dos casos é agropecuária, aos mercados potenciais, fazendo com que seja baixo seu crescimento econômico e populacional; $2^{\circ}$ ) houve redução nos custos de transportes, que culminou na melhoria da acessibilidade, formando as aglomerações. Consequentemente, as grandes aglomerações populacionais passaram a 
demandar produtos da região, gerando crescimento e melhorando as condições socioeconômicas de seus vizinhos. Portanto, as cidades atuam como "indutores de crescimento". A confirmação dessas hipóteses é condizente com os pressupostos defendidos pela NGE.

Além desta introdução, o artigo compõe-se de mais quatro seções. A seguir, é apresentado o arcabouço teórico e analítico, com base no qual este artigo está fundamentado. $\mathrm{Na}$ seção três, são apresentados a metodologia e os dados utilizados para calcular a taxa de crescimento populacional e seus determinantes. Na seção quatro, encontram-se as equações estimadas; e a última seção traz as conclusões do trabalho.

\section{2_A nova geografia econômica $e$ o papel da acessibilidade}

A chamada Nova Geografia Econômica (NGE), entre outros aspectos, estuda a localização da atividade econômica no espaço. Em particular, a NGE é uma vertente da literatura iniciada por Krugman (1991), usando economias de aglomeração para ajudar a explicar o porquê das indústrias se agruparem dentro de determinados países e/ou regiões. Desde então, tem crescido substancialmente o número de teóricos nesse campo e, em menor grau, os trabalhos empíricos. O foco padrão no estudo de aglomeração pela NGE é voltado para aqueles elementos ditos de segunda natureza, como potencial de mercado, densidade do mercado de trabalho e economias externas puras. Por outro lado, há também uma corrente teórica complementar, que considera como fatores geradores da aglomeração os elementos de primeira natureza, como a dotação dos recursos naturais e o clima, por exemplo.

Muitas atividades econômicas são concentradas geograficamente. Todavia, nem todas as pessoas vivem em uma única grande cidade, tampouco a produção de bens na economia está concentrada em um único local. Há um conjunto de forças atuando em direções opostas: de um lado, as forças centrípetas, que tendem a promover a concentração geográfica; e, de outro, as forças centrífugas, agindo no sentido contrário. Forças centrífugas são regidas por efeitos do tamanho de mercado, economias externas puras e mercado de trabalho. Forças centrípetas são regidas por imobilidade de fatores, renda da terra e deseconomias externas puras (Krugman, 1991).

A literatura padrão da NGE está baseada na contribuição seminal do modelo centro-periferia, introduzido por Krugman (1991), que será a base teórica deste trabalho. No referido modelo, utilizam-se alguns mecanismos básicos para modelar uma economia em concorrência monopolista. $\mathrm{O}$ autor destaca que esses mecanismos são um conjunto de técnicas que permitem tratar os problemas da estrutura de mercados propostos pela suposição de que existem retornos crescentes à escala. São eles: a concorrência monopolista de Dixit e Stiglitz e a evolução dos custos de transporte do tipo iceberg de Samuelson. O modelo centro-periferia incorpora os elementos acima descritos. Esse modelo permite a derivação da função potencial de mercado, que neste trabalho será simplificada com o uso do indicador de acessibilidade, seguindo o apresentado por Da Silva (2011). O modelo centro-periferia de Krugman é representado, em síntese, pela seguinte equação:

$$
w_{i}^{D}=\left[\sum_{j=1}^{R} E_{j} P_{j}^{\sigma-1} T_{i j}^{1-\sigma}\right]^{\frac{1}{\sigma}}=M A
$$

A equação acima $^{3}$ é denominada por Reeding e Venables (2004) como Market Access (MA). O salário $w$ dos trabalhadores industriais $D$ em cada localidade $i$ depende positivamente do somatório do nível de renda de cada um dos mercados $\left(E_{j}\right)$ nas regiões $R$ que a empresa atende; negativamente dos custos de transporte entre as diferentes 
localidades $\left(T_{i j}\right)$; e positivamente do nível de preços nos diferentes mercados $\left(P_{j}\right)$. O índice de preço diminui com o número de variedades (empresas) o qual nos permite interpretá-lo como uma medida inversa do grau de concorrência. Portanto, o nível dos salários nominais da indústria na região $i$ depende de uma soma ponderada do poder de compra em todas as regiões acessíveis $j$. $\mathrm{O}$ fator de ponderação é o custo de transporte, que decresce à medida que a distância entre as regiões $i$ e $j$ diminui. Por conseguinte, aquelas regiões com bom acesso a grandes mercados tenderão a pagar salários mais altos como decorrência de reduções nos custos de transportes. Por essa formulação, o acesso ao mercado é o que determina o salário nominal de uma região ofertante. Pode-se notar que o modelo tem dois tipos de forças que afetam a localização das empresas: forças centrípetas (que atraem as empresas para os locais centrais) e forças centrífugas (excluindo-as dos locais centrais). O primeiro tipo de forças seria dado pelo índice de preços - que cria ligações no lado da demanda e dos custos - e pela mobilidade inter-regional dos trabalhadores industriais. O segundo tipo de força é determinado pelos efeitos da concorrência, tanto no mercado de produtos como no de fatores, que eliminam os lucros das empresas.

A estimação da equação (1), potencial de mercado, apresenta muitas dificuldades incluindo dois problemas econométricos importantes: dado que essa equação é não linear, devem-se empregar técnicas de estimação não linear. Além disso, é também frequente ocorrer problemas com endogeneidade que podem viesar a estimação dos parâmetros. Também, não há disponibilidade, em muitos países, de índice de preços dos produtos manufaturados $\left(p_{i}\right)$ a nenhum nível de agregação regional. ${ }^{4} \mathrm{~A}$ solução geralmente encontrada é utilizar o modelo potencial de mercado de Harris (1954) - a ser exposto no item 2.3 - tal como é feito neste trabalho, do qual se deriva o indicador de acessibilidade.

\section{1_Determinantes da aglomeração - \\ novas abordagens à NGE}

Novas abordagens complementares à NGE têm surgido para explicar os processos de aglomerações. Esses trabalhos empíricos buscam testar as hipóteses do modelo básico da NGE levando em conta um conjunto de três alternativas que incorporam novas variáveis, as quais são: 1) as variáveis que medem as vantagens naturais (clima, recursos naturais, por exemplo), também conhecidas como elementos de primeira natureza, abordadas por Gallup et al. (1999), entre outros; b) as variáveis que captam as externalidades geradas pelo capital humano. Supõe-se que regiões dotadas de alta qualificação tendem a atrair grande número de trabalhadores qualificados; $c$ ) variáveis que captam as externalidades do conhecimento, no qual os produtores se beneficiam da proximidade espacial com produtores do mesmo setor, via fluxo de conhecimento produtivo.

A geografia física é altamente diferenciada entre as regiões, e essas diferenças impactam no desenvolvimento econômico. A localização e o clima, por exemplo, têm grandes impactos sobre os níveis de renda, bem como sobre o seu crescimento via mudança nos custos de transporte, na produtividade agrícola, entre outros canais (Gallup et al., 1999). A NGE, por outro lado, demonstra como rendimentos crescentes à escala dos fatores de produção, as economias de aglomeração, os custos de transporte e a diferenciação de produtos podem levar a uma organização espacial altamente diferenciada da atividade econômica entre regiões (países ou municípios). Isso pode ocorrer até mesmo quando as condições físicas subjacentes não são diferenciadas entre essas regiões (Fujita; Krugman; Venables, 2002).

As duas abordagens acima (a da geografia física e da NGE) são complementares. Uma cidade pode surgir, inicialmente, porque tem vantagens nos custos de produção de certos bens ou serviços, decorrentes da sua geografia física 
diferenciada, mas depois pode continuar a progredir como um resultado de economias de aglomeração, mesmo quando a vantagem inicial dos custos tenha desaparecido. Para tanto, os trabalhos empíricos devem ter como objetivo separar as forças do diferencial geográfico e a auto-organização das economias de aglomeração (Gallup et al.,1999). Por essa via, um indicador de acessibilidade auxilia na interpretação dos fatores que promovem o crescimento econômico de determinada região. Este pode ser decorrente de aglomerações, inclusive.

\section{2_A acessibilidade e a localização da atividade econômica}

Conforme destacado, neste trabalho a acessibilidade será uma proxy para o potencial de mercado. Quanto maior é a acessibilidade, maior será a possibilidade de formar aglomerações populacionais, portanto, grandes mercados. Isso ocorre porque, nos grandes mercados, cujo volume da atividade econômica é maior, o salário nominal per capita é igualmente superior, atraindo mais pessoas e formando as aglomerações populacionais. $\mathrm{O}$ indicador de potencial (ou o indicador de acessibilidade) oferece uma medida agregada da área de mercado de certa região, e, quanto mais distante for a região do centro, menor é o potencial. Essa característica levou a uma ampla utilização do modelo potencial para estudos de acessibilidade abordados com base em uma perspectiva econômica. $O$ pressuposto subjacente no uso desse modelo é que as regiões com melhor acesso aos mercados têm maior probabilidade de serem economicamente bem-sucedidas.

A acessibilidade (ou mais precisamente os diferenciais de acessibilidade) pode ser vista como uma ferramenta para promover o desenvolvimento econômico-regional. Baseado nessa argumentação, se a acessibilidade das regiões periféricas aumentasse, a importância da localização diminuiria. Então, seria possível ocorrer um deslocamento da produção para regiões com salários mais baixos. Isso estimularia a atividade econômica nessa região periférica, aproximando-a do nível das regiões centrais. O contrário pode ocorrer com a drenagem de recursos para regiões centrais (Paez, 2004).

Compreender a localização da atividade econômica remete à acessibilidade. Behrens e Thisse (2007) destacam a importância da compreensão teórica das interdependências espaciais para orientar a análise empírica. $O$ ponto de partida, segundo os autores, é que a acessibilidade aos mercados varia entre as regiões. Fricções espaciais entre duas regiões podem ser diferentes, as quais significam que a posição relativa de uma região dentro da rede de interação é muito importante. Os autores citam como exemplo que até mesmo o mais simples modelo de localização de uma firma leva em conta o acesso aos vários mercados. Esse acesso é fator determinante para o processo de escolha da localização. Em suma, acessibilidade é crucial para a previsão de como o tamanho do mercado local afeta a localização da atividade econômica.

\section{3_0 Índice de Acessibilidade proposto para a Região Norte}

O debate sobre os conceitos de acessibilidade, sua importância e aplicabilidade reforçam a necessidade de se ter um indicador dessa natureza para a Região Norte. Nela há concentração da atividade econômica em poucas cidades, e estas, por sua vez, estão em desvantagem aos principais centros urbanos do país. De maneira direta, o acesso das cidades da Região Norte aos grandes mercados é dificultado pela distância geográfica, que pode ser uma das principais causas das desigualdades econômicas e populacionais lá evidenciadas.

De modo a quantificar esse isolamento, Da Silva (2011) propõe um indicador de acessibilidade para a Região Norte. Esse indicador segue o padrão potencial de mercado de 
Harris (1954), o qual foi utilizado por Krugman na formulação da NGE. O indicador é o seguinte:

$$
A_{i}=\frac{\sum_{j} W_{j}^{-\alpha c_{i j}}}{W_{j R}}
$$

em que $A_{i}$ é o potencial de mercado ou a acessibilidade do município $i ; \sum_{j} W_{j}$ é soma da medida de massa dos mercados potenciais $j$ a serem alcançados por $i ; W_{j R}$ é o mercado potencial de referência; $c_{i j}$ é a medida da distância de $i$ a $j$, equivalente ao custo de transporte; e $\alpha$ é o parâmetro de decaimento exponencial da distância. Pela formulação acima, quanto maior é o valor de $-\alpha c_{i j}$, menor é a acessibilidade do município, e, quanto menor é , maior é a acessibilidade do município $i$. A ponderação pelo mercado potencial de referência $W_{j R}$ visa comparar o Índice de Acessibilidade das cidades da Amazônia com o maior Índice de Acessibilidade possível, ${ }^{5}$ dentro das fronteiras do Brasil, que nesse caso será a cidade de São Paulo, dado que esse é o maior mercado consumidor brasileiro. $\mathrm{O}$ Índice de Acessibilidade resultante pode ser interpretado como o percentual de acesso aos mercados em relação ao maior mercado consumidor.

Para obter a medida de acessibilidade da equação (2), Da Silva (2011) considerou a intermodalidade de transporte da Região Norte (fluvial e rodoviário) e a população de todos os municípios nos anos 1980 e 2000. Não obstante exista o modal ferroviário e o aéreo na referida região, esses não foram considerados no índice. Somente os Estados do Pará e do Amapá possuem ferrovias, que, por sua vez, chegam a poucos municípios, tornando-as irrelevantes para a análise. $O$ modal aéreo, em razão dos seus elevados custos, é relativamente pouco usado, e a maioria das pessoas se locomove por rodovias e rios. O mesmo se aplica para o sistema de cargas. ${ }^{6}$
A acessibilidade de um município $i$ é medida pela sua facilidade de acesso a um grande mercado $j$. Esse mercado $j$ são as cidades ${ }^{7}$ com população $W$ acima de 100 mil habitantes, no ano de 1980, mais a cidade de São Paulo. A acessibilidade pode ser entendida como a facilidade de se chegar a um destino. Ela será medida pelo tempo de viagem da origem $i$ ao destino $j$, e esse tempo de viagem levará em conta a intermodalidade entre os modais fluvial e rodoviário. A função exponencial da equação (2) é utilizada para modelar o efeito de decaimento da distância no score da acessibilidade. $O$ decaimento da função exponencial na equação (2) é regido pelo parâmetro $\alpha$. Esse parâmetro é antecedido com um sinal negativo e tem valor igual a 1 por convenção, uma vez que ele é o indicador do efeito negativo da distância (O'Kelly; Horner, 2003). O valor de $c_{i j}$ é obtido da seguinte forma:

$$
c_{i j}=\left[\frac{D_{i j r}}{V_{r}}+\frac{D_{i j f}}{V_{r f}}+\theta\right]
$$

Em que $D_{i j r}$ é a distância do município $i$ ao município $j$ pelo modal rodoviário $r ; D_{i j r}$ é a distância de $i$ a $j$ pelo modal fluvial $f ; V_{r}$ e $V_{r f}$ são as velocidades médias dos modais rodoviário e fluvial, respectivamente; $\theta$ é o tempo de transferência de um modal para outro. Dessa forma, tomando-se a população do mercado potencial $j$, elevado ao expoente $-\alpha c_{i j}$ e dividindo pelo mercado de referência $W_{j R}$, obtém-se o Índice de Acessibilidade ou Potencial de Mercado para os municípios da Região Norte conforme a equação (2).

\section{3_Metodologia e dados}

Inicialmente, é apresentada a equação a ser estimada e, em seguida, discutem-se os procedimentos de econometria 
espacial a serem empregados. Por causa da fragmentação e/ou da criação de outros municípios na Região Norte, entre 1980 e 2000, as variáveis a serem analisadas devem ser agrupadas em áreas mínimas comparáveis (AMC), o que será analisado no item 3.2. Por fim, os dados e as fontes desses são discutidos no item 3.3.

Para a modelagem empírica da NGE, parte-se da expressão (1), potencial de mercado da NGE, que, por sua vez, será mensurada pela proxy $A_{i}$ na equação (2), que é $\mathrm{o}$ indicador de acessibilidade. A acessibilidade será utilizada como variável de segunda natureza, explicativa das aglomerações. Complementarmente, serão utilizadas as variáveis de primeira natureza, comumente aplicadas nas pesquisas complementares ao modelo básico da NGE.

A simplificação é uma necessidade nos trabalhos empíricos da NGE, embora essa tenha se desenvolvido bastante no campo teórico. Autores como Head e Mayer (2004), Neary (2001) e Ottaviano e Pinelli (2006) concordam que a pesquisa empírica na NGE ainda é deficiente, mas que há maneiras bem-sucedidas de testar a validade das forças que atuam sobre seus modelos. Trata-se de analisar os choques na renda causados pela distância dos mercados consumidores, ou seja, pela verificação (ou não) da chamada equação dos salários nominais (potencial de mercado), obtidos a partir da derivação de um modelo padrão da NGE. A estimativa dessa equação tem sido o maior desafio nos trabalhos empíricos que tentam validar as premissas do modelo. Pelas dificuldades de implementação empírica, a maioria das pesquisas tem feito simplificações no modelo, como em Amaral et al. (2007), do mesmo modo que será feito neste artigo.

$\mathrm{O}$ crescimento populacional dos municípios da Região Norte será analisado no período de 1980 a 2000. O modelo está baseado em Andersen et al. (2002) e Partridge et al. (2007) e será implementado valendo-se de uma função utilidade indireta derivada do ajustamento das firmas e das famílias representativas. Esse ajustamento leva em consideração os fatores de economias de aglomeração e amenidades naturais, bem como efeitos de congestão, isto é, os fatores de primeira e segunda natureza. Serão utilizadas as dummies para os dados invariantes no tempo, como latitude, altitude, longitude, pluviosidade e proximidade de centros urbanos. A representação de forma reduzida do modelo a ser estimado é:

$$
\begin{array}{r}
\Delta \operatorname{pop}_{i(t 1-t 0)}=\alpha+\beta \Delta A_{i(t 1-t 0)}+\gamma \Delta A G_{i(t 1-t 0)}+ \\
+\delta \Delta E S_{i(t 1-t 0)}+\varepsilon_{i(t-0)}
\end{array}
$$

Onde: $p o p$ é a população; $A$ representa o potencial de mercado, mensurado através do Índice de Acessibilidade e que capta a infraestrutura de transporte; $A G$ corresponde às variáveis que captam as amenidades naturais dos municípios, chamadas de elementos de primeira natureza, que correspondem à latitude, à altitude, à longitude, à pluviosidade e à proximidade das pequenas cidades aos grandes centros urbanos, todas representadas por dummies (como será explicado no item 3.3); ES são as variáveis econômicas e sociais, como salários, participação do emprego rural e urbano e Índices de Desenvolvimento Humano IDHs; as letras gregas $\alpha, \beta, \gamma$ e $\delta$, são os coeficientes de regressão e $\varepsilon$ o termo de erro. A variável dependente é a taxa de variação populacional (em logaritmos) no período de 1980 a 2000, e as variáveis explanatórias de segunda natureza estão em taxa de crescimento. ${ }^{8}$

A equação (4) será estimada separadamente para avaliar o crescimento da população rural e o da população urbana. $\mathrm{O}$ objetivo de diferenciar os espaços rurais e urbanos é verificar se é válida a suposição das cidades como "indutores de crescimento".

Os mercados potenciais jsãotodas as cidades existentes em 1980 com população acima de 100 mil habitantes. ${ }^{9}$ Os mu- 
nicípios $i$ são todas as cidades existentes em 1980, incluindo o próprio mercado potencial, totalizando 205 unidades. Da Mata et al. (2005) afirmam que no Brasil não existe uma definição do que é uma grande aglomeração populacional. Nas suas abordagens, os autores seguem os padrões do Instituto Brasileiro de Geografia e Estatística (IBGE) e do Instituto de Pesquisa Econômica Aplicada (IPEA). No presente trabalho, o corte a ser realizado tem como base o fato de que mais de $95 \%$ dos municípios da Região Norte têm população abaixo de 100 mil, sendo os municípios com população superior a esse limite considerados grandes aglomerações em termos regionais.

\section{1_0 modelo empírico com econometria espacial}

Inicialmente, a equação (4) será estimada por meio do método dos Mínimos Quadrados Ordinários. Caso os resíduos da regressão dos municípios sejam espacialmente correlacionados com municípios vizinhos (em que a força da correlação é inversamente relacionada à distância entre os dois municípios), serão utilizados os métodos da econometria espacial. Para testar o impacto dos efeitos de vizinhança e melhorar o entendimento da dinâmica espacial do crescimento da população, que não são captados pelos métodos tradicionais de econometria, será incorporada à equação (4) a matriz de pesos espaciais, $\Omega$. Essa matriz é o instrumento que se desenvolveu para captar a interdependência entre unidades espaciais.

O conceito de matriz de pesos espaciais tem como base a contiguidade, que pode ser definida conforme a vizinhança, a distância geográfica ou socioeconômica, ou a combinação das duas. A escolha da matriz de pesos é relevante, uma vez que os resultados podem variar dependendo da matriz considerada. Essa matriz tem como característica ser quadrada, e não estocástica, cujos elementos $w_{i j}$ refletem a intensidade da relação existente entre cada par de unidades ${ }^{10} i$ e $j$.A proximidade pode ser medida de muitas formas; por essa razão, existem várias especificações para $\Omega$. Neste trabalho, utilizou-se uma matriz de contiguidade de primeira ordem e com critério rainha para definir a vizinhança. A sua diagonal principal contém zeros, e fora da diagonal surgem valores 0 ou 1 , que refletem a proximidade espacial de cada par de áreas $i$ e $j$. Isso significa que municípios com divisa comum são iguais a 1, e sem vizinhança, iguais a zero. Assim, choques ou variações num município podem causar ou não efeitos no seu vizinho. As regressões espaciais a serem estimadas são:

$$
\begin{aligned}
& \begin{array}{l}
\Delta \operatorname{pop}_{i(t 1-t 0)}=\rho \Omega \Delta \operatorname{pop}_{i(t 1-t 0)}+\Delta X_{t 1-t 0} \beta+\varepsilon_{i} \\
(\text { defasagem espacial) })
\end{array} \\
& \varepsilon_{i}=\lambda \Omega \varepsilon_{i}+u_{i s(t 1-t 0)} \\
& \Delta \operatorname{pop}_{i(t 1-t 0)}=\Delta X_{t 1-t 0} \beta+(I-\lambda \Omega)^{-1} u_{i} \\
& (\text { erro espacial) })
\end{aligned}
$$

Em que pop é a população do município $i$ no instante $t$; $\rho$ e $\lambda$ são parâmetros escalares autorregressivos da matriz de pesos espaciais $\Omega$; e, o vetor de erro é $u_{i s} \sim N\left(\mathrm{o}, \sigma^{2}\right.$, i.i. $d^{13}$.), $\beta$ é o vetor $\mathrm{k} x \mathrm{de}$ coeficientes da matriz de características $X$. De forma a sintetizar o modelo, todos os coeficientes da regressão em (4) são representados por $X$ nos modelos (5) e (7).

Conforme Anselin (1988), os modelos em (5) e (7) são autorregressivos espaciais homocedásticos, isto é, têm distribuição de frequência com padrão regular. Há dois casos particulares de modelos econométricos espaciais: modelo com defasagem espacial (equação 5) e modelo com erro espacial (equação 7). Se $\lambda=0$ em (6), tem-se um modelo com defasagem espacial como em (5), implicando que o crescimento populacional das cidades vizinhas influencia, 
no mesmo sentido, a cidade $i$. Se $\rho=0$, tem-se um modelo com erro espacial, como em (7), pressupondo que o crescimento de uma cidade depende de alguma associação espacial de uma variável qualquer que não foi incluída no modelo. $\mathrm{O}$ instrumento de diagnóstico usado para identificar um termo de erro autorregressivo espacialmente ou uma defasagem espacial erroneamente omitida são os testes dos multiplicadores de Lagrange. Para identificar o modelo econométrico adequado para estimar a equação (4), adota-se o procedimento sugerido por Florax et al. (2003).

Os efeitos espaciais apresentados podem ser divididos em duas categorias: heterogeneidade espacial e dependência espacial, também conhecida como autocorrelação espacial. A heterogeneidade espacial surge quando se usam dados de unidades espaciais distintas para explicar um mesmo fenômeno. Neste caso, aparecem problemas como a heterocedasticidade ou a instabilidade estrutural, os quais podem ser resolvidos mediante técnicas econométricas padrões, como, por exemplo, pelo uso do Método dos Mínimos Quadrados Ponderados. Por sua vez, a autocorrelação espacial surge ao passo que o valor de uma variável em um lugar do espaço está relacionado com o valor de tal variável em outros lugares. Conforme isso se apresente, faz com que se viole uma das principais hipóteses quando se trabalha com dados de corte transversal. Isso tem a ver com a independência das observações amostrais, a qual conduz a problemas de ineficiência em qualquer estimação feita por Mínimos Quadrados Ordinários (Moreno; Vaya, 2000).

Para verificar a presença ou não de autocorrelação espacial, deve-se recorrer a um teste estatístico, o I de Moral global, que resume o esquema geral de dependência. Dado que os testes de autocorrelação espacial global analisam todas as observações da amostra de forma conjunta, eles não captam situações nas quais predomine uma importante instabilidade na distribuição espacial da variável em es- tudo. Esses testes não contemplam a possibilidade de que 0 esquema de dependência detectado em nível global possa não se manter em todas as unidades do espaço analisado. Tal limitação é superável por meio do cálculo da estatística local de Moran, LISA (Anselin, 1988).

\section{2_As Áreas Mínimas Comparáveis (AMC)}

Durante o período em análise (1980 a 2000), ocorreram expressivas modificações na rede de municípios da Região Norte que aconteceram, simultaneamente, à elevação de categoria de Território para Estado, como o caso de Rondônia, em 1982; Amapá e Roraima, em 1991; e a criação do Estado de Tocantins, em 1989, que antes fazia parte do Estado de Goiás. Essas alterações colocam problemas para comparações municipais entre anos censitários (Reis et al., 2008). Sob esse aspecto, analisar o comportamento de uma variável de um município que foi desmembrado para gerar outros é uma tarefa complexa. Por isso que a solução usualmente encontrada se dá através de áreas mínimas comparáveis (AMC). Para calculá-las, será utilizada a metodologia proposta por Da Silva e Bacha (2011), que consiste em criar as AMC via polígono de Voronoi.

Essa metodologia permite que a base de municípios ${ }^{11}$ de 1980 seja a mesma de 2000. Portanto, os municípios que foram criados a partir de 1980 são agregados às suas bases geradoras, mas considerando a menor distância entre eles, e não as áreas territoriais. Uma vez criadas as AMC, ponderam-se as variáveis censitárias que são alocadas nas suas respectivas AMC. Esse método capta tanto a perda de população resultante do desmembramento como também o movimento migratório intermunicipal de zonas rurais e urbanas. O método é aplicado para todas as variáveis explicativas, exceto para as variáveis de primeira natureza, já que elas são dummies (como explicado a seguir). 


\section{3_Variáveis e fonte de dados}

A base de dados foi construída com base na consolidação dos Censos Demográficos de 1980 e 2000 e Agropecuários de 1980 e 1996. O Índice de Acessibilidade, as AMC, bem como a ponderação das variáveis nas AMC, foram obtidos baseando-se em Da Silva (2011). Informações complementares, como condições de rodovias, mapas atuais, foram extraídas do Banco de Dados da Amazônia (BADAM), do Departamento Nacional de Infraestrutura de Transporte (DNIT) e do Instituto Nacional de Pesquisas Espaciais (INPE).

As variáveis classificadas como de primeira natureza apresentam oscilações mínimas no tempo. Para evitar variação zero no modelo empírico deste trabalho, adotou-se dummy para captar seus efeitos sobre as aglomerações populacionais. As variáveis geográficas altitude e longitude foram combinadas em uma única variável dummy para captar os efeitos de tempo de viagem. Como ambas têm suas medidas iniciais a partir do Oceano Atlântico, para obter essa dummy altitude-longitude, dividiu-se por 2 a maior distância euclidiana observada de oeste a leste da Região Norte. Todos os municípios localizados à esquerda da linha divisória têm valor igual a 1 , e à direita, igual a zero.

A altitude-longitude, além de influenciar na distância, deverá captar também o efeito do contrafluxo dos rios, já que, na bacia amazônica, à medida que se aproxima da cordilheira dos Andes, o fluxo dos rios é relativamente mais intenso. O mesmo procedimento foi adotado para a dummy de latitude, tendo em vista que a maioria dos municípios está localizada abaixo da linha do Equador. Essa variável tem a função de captar os efeitos da temperatura. Então, dividiu-se a distância do extremo norte da região ao extremo sul por 2. Deste modo, os municípios ao norte dessa linha divisória receberam o valor de 1, e aqueles ao sul, o valor de zero. Outra variável de primeira natureza é a dummy para captar os efeitos de proximidade às capitais. Aqueles municípios próximos à respectiva capital do Estado num raio de 100 quilômetros têm valor 1, e os demais, valor 0 .

Para captar os efeitos da pluviosidade na formação de aglomerações populacionais, adotou-se o seguinte procedimento: a) a proporção do índice pluviométrico da Região Norte em relação a cada região do Brasil; b) extraiu-se o percentual de imigrantes de cada Estado da Região Norte, por origem de UF (Unidade Federativa); c) multiplicou-se a proporção de pluviosidade pela taxa de imigração, para cada Estado da Região Norte; d) somaram-se os valores obtidos no item anterior, por UF; e) extraiu-se a média dos valores calculados no item $d$ ) para depois atribuir o valor de 1 aos Estados com somatório acima da média e 0 para aqueles abaixo da média. Como exemplo, seja o caso para o Estado do Acre. $O$ índice pluviométrico da Região Norte em relação ao Nordeste é 2,05. Em relação ao Sudeste, é 1,51; em relação ao Sul, 1,27; e ao Centro-Oeste, 1,26. O percentual do total de imigrantes do Acre advindos do Nordeste, entre os anos 1980 e 1991, foi de 0,7\%; do Sudeste, 1,6\%; do Sul, 1,7\%; e do Centro-Oeste, $1,6 \%$. Multiplicando as taxas e somando, tem-se: $2,05 \times 0,007+1,51 \times 0,016+1,27 \times 0,017+1,26 \times 0,016=$ 0,08 . Repete-se esse mesmo procedimento para todos os outros Estados da Região Norte. No final, supondo que a média dos nove Estados da Região Norte seja de 0,9, então todos os municípios do Acre receberão o valor de 0 (zero), visto que o resultado é inferior à média para os nove Estados.

Obviamente, esse método tem deficiência, uma vez que todos os municípios de um Estado receberão o mesmo valor para a dummy. No entanto, pode-se inferir se a taxa de emigração da Região Nordeste para o Norte tem influência da pluviosidade. Adotou-se esse procedimento, primeiramente, porque não foi encontrada na literatura nenhuma pesquisa que se enquadrasse no caso em estudo. Em segundo, nas décadas passadas, a seca do Nordeste era uma das principais causas de migração para a Região Norte, e, até os dias atuais, 
a maior taxa de imigração para a Região Norte advém da Região Nordeste. Portanto, como o Nordeste tem a maior taxa de emigração para o Norte como também a menor taxa de pluviosidade do Brasil, é de se esperar que a pluviosidade do Norte deve ter alguma influência sobre o migrante oriundo do Nordeste e, em menor proporção, sobre os migrantes oriundos das demais regiões do país.

\section{4_Resultados das regressões estimadas}

Os testes estatísticos indicaram a presença de autocorrelação espacial e heterogeneidade espacial nas estimativas da equação (4) tanto para o crescimento da população rural quanto da urbana (ver Tabela A.1 no Anexo). Em razão disso, estimou-se um modelo com a adição da variável de interação entre a população e a acessibilidade para corrigir a heterocedasticidade. Para o caso da autocorrelação espacial, estimou-se nova equação incorporando o componente espacial, que compreende um método com erro espacial [equação (7)] e outro com defasagem espacial [equação (5)]. No método com defasagem espacial e erro espacial, os parâmetros rho e lambda refletem a dependência espacial inerente à amostra de dados, medindo a influência média das observações dos seus vizinhos. Isso significa que, se há uma mudança da variável em análise em um local, seus vizinhos serão afetados por essa mudança, em média, equivalente ao valor do coeficiente rho ou lambda. Nos resultados das Tabelas 1 e 2, a baixa probabilidade desses coeficientes confirma o padrão espacial já identificado quando feito o teste I de Moran (proposto por Anselin, 1988). Ver Tabela A.1 no Apêndice.

Visto que o método com a defasagem espacial é o mais adequado para corrigir as imperfeições do modelo já discutidas, a seguir (Tabela 1) são apresentados os resultados com os devidos ajustes para o crescimento da população rural.
Os testes indicaram que o método adequado para estimar o modelo para o crescimento da população urbana é com erro espacial. A Tabela 2 apresenta esses resultados, e, tal como ocorreu na regressão para explicar as taxas de crescimento da população rural, as variáveis de primeira natureza não se mostraram estatisticamente significativas. Realizaram-se novas regressões somente com as variáveis significativas (ver Tabelas A.2 e A.3 no Apêndice). Contudo, os novos coeficientes são bem próximos aos das Tabelas 1 e 2 e com os mesmos sinais. Por isso, optou-se por analisar no texto os resultados das Tabelas 1 e 2.

Tabela 1_Estimativa da equação (5), para o crescimento da população rural (período de 1980 a 2000), com defasagem espacial

\begin{tabular}{|c|c|c|c|c|c|}
\hline \multirow{2}{*}{$\begin{array}{l}\text { Variável } \\
\text { Rho }\end{array}$} & \multirow{2}{*}{$\begin{array}{r}\text { Coeficiente } \\
0,202 \\
\end{array}$} & \multirow{2}{*}{ 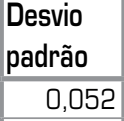 } & \multirow{2}{*}{\begin{tabular}{|l} 
z valor \\
3,920 \\
\end{tabular}} & \multicolumn{2}{|c|}{ Probabilidade } \\
\hline & & & & 0,000 & **\% \\
\hline Intercepto & $-0,023$ & 0,833 & $-0,028$ & 0,978 & \\
\hline Pluviosidade & 0,125 & 0,153 & 0,816 & 0,415 & \\
\hline Altitude-Longitude & $-0,052$ & 0,047 & $-1,112$ & 0,266 & \\
\hline Latitude & $-0,033$ & 0,030 & $-1,112$ & 0,266 & \\
\hline Prox. Capitais & $-0,003$ & 0,044 & $-0,065$ & 0,948 & \\
\hline $\begin{array}{l}\text { Imp. PEA urb. } \\
\text { Emprego }\end{array}$ & $-0,242$ & 0,043 & $-5,575$ & 0,000 & ***\% \\
\hline $\begin{array}{l}\text { Imp. PEA rur. } \\
\text { Emprego }\end{array}$ & 0,480 & 0,042 & 11,476 & 0,000 & **** \\
\hline IDH-Educação & 0,242 & 0,091 & 2,658 & 0,008 & *** \\
\hline IDH-Longevidade & $-0,380$ & 0,180 & $-2,111$ & 0,035 & 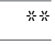 \\
\hline IDH-Renda & $-0,304$ & 0,062 & $-4,901$ & 0,000 & ***\% \\
\hline Salário Rural & 0,429 & 0,031 & 13,989 & 0,000 & ***\% \\
\hline PM (Acessibilidade) & $-0,749$ & 0,118 & $-6,339$ & 0,000 & $* * *$ \\
\hline $\begin{array}{l}\text { Interação } \\
\text { (pop. e acess.) }\end{array}$ & 0,598 & 0,073 & 8,178 & 0,000 & 萂: \\
\hline
\end{tabular}

Fonte: Elaborada com base nos dados da pesquisa e do programa SpaceStat. Notas: ${ }^{* *}$ significativo a $1 \%$; ${ }^{* *}$ significativo a $5 \%$; ${ }^{\star}$ significativo a $10 \%$. Imp.PEA urb.Emprego = Importância da população economicamente ativa, urbana, no emprego total.

Imp. PEA rur. Emprego = Importância da população economicamente ativa rural no emprego total. 
Tabela 2_Estimação da equação (7), para a população urbana, com erro espacial

\begin{tabular}{|c|c|c|c|c|c|}
\hline Variável & Coeficiente & $\begin{array}{l}\text { Desvio } \\
\text { padrão }\end{array}$ & z valor & \multicolumn{2}{|c|}{ Probabilidade } \\
\hline Lambda & 0,296 & 0,094 & 3,157 & 0,002 & 前前 \\
\hline Intercepto & $-0,677$ & 0,963 & $-0,702$ & 0,483 & \\
\hline Pluviosidade & 0,144 & 0,178 & 0,810 & 0,418 & \\
\hline Altitude-Longitude & $-0,031$ & 0,065 & $-0,476$ & 0,634 & \\
\hline Latitude & 0,053 & 0,033 & 1,639 & 0,101 & \\
\hline Prox. Capitais & 0,079 & 0,044 & 1,813 & 0,070 & \\
\hline $\begin{array}{l}\text { Imp. PEA urb. } \\
\text { Emprego }\end{array}$ & 0,159 & 0,042 & 3,782 & 0,000 & 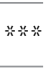 \\
\hline $\begin{array}{l}\text { Imp. PEA rur. } \\
\text { Emprego }\end{array}$ & $-0,052$ & 0,031 & $-1,647$ & 0,100 & \\
\hline IDH-Educação & 0,152 & 0,092 & 1,646 & 0,100 & \\
\hline IDH-Longevidade & $-0,290$ & 0,180 & $-1,614$ & 0,107 & \\
\hline IDH-Renda & $-0,398$ & 0,061 & $-6,496$ & 0,000 & 前前并 \\
\hline Salário Urbano & 0,642 & 0,030 & 21,520 & 0,000 & 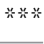 \\
\hline PM (Acessibilidade) & 0,200 & 0,070 & 2,856 & 0,004 & $\because \%$ \\
\hline $\begin{array}{l}\text { Interação } \\
\text { (pop. e acess.) }\end{array}$ & $-0,073$ & 0,107 & $-0,681$ & 0,496 & \\
\hline
\end{tabular}

Fonte: Elaborada com base nos dados da pesquisa e do programa SpaceStat. Notas: ${ }^{* * *}$ significativo a $1 \% ;{ }^{* *}$ significativo a $5 \%$; ${ }^{\star}$ significativo a $10 \%$.

\section{1_Os efeitos das variáveis de primeira natureza}

Apesar de não ser estatisticamente significativa, a variável Altitude-Longitude apresentou o sinal esperado (ver Tabelas 1 e 2). Partindo de Belém, via modal fluvial, rumo a oeste da Amazônia, todos os rios estarão no contrafluxo. Isso implica que, enquanto uma viagem de Porto Velho a Belém pode durar sete dias, no caminho contrário pode dobrar, dependendo da época do ano. ${ }^{12}$ Então, quando mais a oeste estiver o município, maior será o tempo de viagem do litoral até ele. Daí uma das razões do efeito negativo da variável Altitude-Longitude sobre o crescimento da população, uma vez que, apesar de ser uma planície, no Sudoeste há altitudes de até 220 metros (no Acre). Em termos de fluxo de água, essa altitude tem grande representatividade. Ainda, há que se considerar que, historicamente, a população tende a se concentrar no litoral. Logo, quanto mais distante estiver o município do litoral, menor tende a ser o crescimento de suas populações das zonas rurais e urbanas.

A variável Pluviosidade também teve o sinal esperado, apesar de não ser estatisticamente significativa. Quanto maior é a pluviosidade, maior é o crescimento populacional. Já a variável Latitude teve efeito negativo no crescimento das populações rurais e positivo no crescimento das populações urbanas, mas ambas sendo não estatisticamente significativas.

A variável Proximidade aos Grandes Centros apresentou os sinais esperados (negativo na equação de crescimento da população rural, e positivo no crescimento da população urbana) e seu coeficiente foi estatisticamente significativo apenas na equação que explica o crescimento da população urbana. Esse resultado na Tabela 2 vai ao encontro da hipótese de as grandes cidades serem "indutores do crescimento", ou seja, aquelas cidades menores e mais próximas dos grandes centros regionais - como as capitais Manaus, Porto Velho, Belém, Rio Branco, Boa Vista, Palmas e Macapá - estão crescendo mais do que as cidades mais distantes. Esse resultado reflete também as externalidades positivas com o transbordamento da informação. Nas capitais, estão centralizadas as forças político-regionais, muitas vezes responsáveis por decisões importantes para levar ao desenvolvimento local. Estar próximo a esses centros de poder representa grande vantagem para as populações de cidades vizinhas. Na regressão para mudanças na população rural (Tabela 1), essa variável não foi estatisticamente significante e teve sinal negativo (resultado coerente com a argumentação de Ades e Glaeser (1995), sobre o âmbito em que se tomam algumas decisões que afetam a população rural). 


\section{2_Os efeitos das variáveis de segunda natureza}

As variáveis de segunda natureza são as que mais influenciaram a formação das aglomerações populacionais da Região Norte, explicando tanto o crescimento das populações rurais quanto o das urbanas. Entre 1980 e 2000, houve intensa mudança na distribuição entre população rural e urbana na Região Norte, com crescimento desta última. Essa mudança é refletida nas variações positivas da participação do emprego nas zonas urbanas, que causou efeito negativo sobre o crescimento das populações das zonas rurais (ver variável Imp. PEA urb. Emprego na Tabela 1).

De acordo com os resultados contidos na Tabela 1, para cada aumento de $1 \%$ da importância dos empregos gerados nas zonas urbanas, haverá redução da taxa de crescimento da população rural em $0,24 \%$. Apesar desse efeito negativo, ao longo dessas duas décadas, as oportunidades de emprego criadas nas zonas rurais da Região Norte foram importantes. Os Estados de Rondônia e Pará, por exemplo, obtiveram ampla expansão das zonas rurais, estimulados pelos programas de apoio à agropecuária ainda na década de 1970. As pessoas que migraram entre 1980 e 1990, por padrão, vislumbravam muitas oportunidades na exploração dos recursos naturais, em abundância na Região Norte. Provavelmente, o coeficiente positivo das variáveis Participação de Emprego Rural e Imp. PEA rur. Emprego, na Tabela 1 (afetando o crescimento da população rural) reflete essa política de estímulo dos anos 1970 - que tem efeitos duradouros, sobretudo no processo migratório - tanto que, para cada 1\% de aumento da participação do emprego rural, a taxa de crescimento da população rural aumentou $0,48 \%$, ou seja, a possibilidade de explorar os recursos naturais demonstrou força de atração de população.

Todavia, enquanto a oferta de emprego nas cidades teve grande impacto negativo no crescimento da população rural, essa mesma variável teve menor força positiva no cres- cimento da população urbana. Para cada aumento de $1 \%$ na variável Imp. PEA urb. Emprego, há 0,159\% de aumento na taxa de crescimento da população urbana (Tabela 2) e queda de $0,242 \%$ na taxa de crescimento da população rural (Tabela 1). Além disso, o aumento do emprego na zona rural (variável Imp. PEA rur. Emprego) tem efeito expressivo no crescimento da população da própria zona rural $(0,48 \%$, Tabela 1) e pouco efeito no crescimento da população da zona urbana (-0,05\%, Tabela 2$)$. 0 resultado acima permite deduzir que é mais fácil manter o homem empregado no campo que tirá-lo da cidade. Então, políticas públicas de estímulo à geração de emprego nas zonas rurais têm mais efeitos no crescimento populacional rural que políticas similares aplicadas nas zonas urbanas, por exemplo.

Diante desses resultados, parece claro que ainda há alguma força econômica que mantém o homem no campo na Região Norte. Provavelmente, essa força é oriunda da demanda por produtos agrícolas das maiores cidades, que indiretamente dão suporte aos salários rurais (que afetam positivamente o crescimento da população rural - ver Tabela 1). Ademais, não há sinais de que a exaustão dos recursos naturais esteja gerando redução de salários rurais. Caso esse efeito da exaustão existisse, provavelmente o coeficiente da variável Salário seria negativo e ocorreria migração expressiva das zonas rurais para as urbanas.

Os resultados das Tabelas 1 e 2 sugerem que as maiores cidades estão atuando como "indutores do crescimento”. Os indícios dessa hipótese podem ser observados no Índice de Acessibilidade, por exemplo, com forte impacto negativo no crescimento da população rural (coeficiente de -0,749) e positivo no crescimento da população urbana (coeficiente de 0,200). A participação do emprego na zona urbana também dá indícios das cidades atuando como indutores do crescimento. Outra variável importante para mostrar essa evidência é a Proximidade de Capitais, 
com efeito positivo e estatisticamente significativo no crescimento da população urbana e efeito negativo (ainda que estatisticamente não significativo) sobre o crescimento da população rural.

O aumento do emprego rural tem pouca influência na atração de pessoas das zonas urbanas (coeficiente de -0,052 da variável Imp. PEA rur. Emprego na Tabela 2). Esse resultado reflete, em menor intensidade, as forças desaglomerativas, isto é, os efeitos de congestão ou a atuação das forças centrífugas. Os efeitos de congestão estão ligados a fatores diversos, como poluição nas zonas urbanas, alto custo de vida, criminalidade, entre outros.

A variável $I D H-R e n d a$ (cujos coeficientes têm sinal negativo nas Tabelas 1 e 2) é uma boa representante das forças centrífugas, pois pode ser usada como proxy para o alto custo de vida, no caso das cidades ou, para o baixo nível de renda, no caso das zonas rurais. Nestas últimas, o nível de renda geralmente está no limite inferior do $\mathrm{IDH}$ -Renda. Isso leva as pessoas a migrarem para outras localidades em busca de melhores condições de vida. No caso das zonas urbanas, esse indicador sugere efeitos de congestão ou a atuação das forças centrífugas. Inicialmente, as pessoas são atraídas por salários maiores, porém, nas áreas urbanas o custo de vida é mais elevado e isso é decorrente do aumento da densidade populacional, que aumenta o preço da habitação (Glaeser et al., 1995).

A permanência dos migrantes das zonas rurais nas zonas urbanas aumenta as estatísticas de pessoas com renda abaixo da linha de pobreza. Provavelmente, são essas as razões que levaram à queda do IDH-Renda em diversos municípios da Região Norte, entre os anos de 1980 e 2000. Daí seus efeitos negativos no crescimento populacional.

$\mathrm{O}$ coeficiente negativo associado ao IDH-Longevidade não necessariamente reflete efeitos de congestão. $\mathrm{O}$ aumento da qualidade de vida, medido pelo $I D H$-Longe- vidade, implica redução da taxa de fecundidade, que, por sua vez, reduz a participação dos jovens na distribuição etária da população, ocasionando também a redução populacional (Wong, 2001). À medida que sabem que vão viver mais, além da melhoria do nível educacional e da baixa renda, as pessoas tendem a ter menos filhos e a aumentar a sua taxa de poupança para garantir um futuro melhor, por isso o aumento do IDH-Longevidade reduz as taxas de crescimento das populações urbana e rural. Vale destacar que o aumento da expectativa de vida não está diretamente relacionado a maiores níveis de renda (em razão dos avanços da medicina e aos programas públicos de vacinação e saúde). Portanto, é possível ter aumento da expectativa de vida sem, necessariamente, ter aumento de renda.

As evidências observadas na literatura da NGE indicam que há ganhos substanciais de produtividade com o transbordamento da informação (spillovers) e isso é decorrente da melhor qualificação da mão de obra. Pessoas com melhor qualificação recebem maiores salários, da mesma forma que as empresas se instalam onde a mão de obra é mais qualificada (Krugman, 1991). Os resultados obtidos nas Tabelas 1 e 2 demonstram essas implicações por meio das variáveis $I D H$-Educação e Salário. Teoricamente, era de se esperar que o sinal do coeficiente da variável $I D H$ -Educação fosse negativo para zonas rurais e positivo para zonas urbanas. No entanto, em ambas as regressões, essa variável sugere que há aumentos populacionais decorrentes das melhorias nesse indicador.

Quanto à variável Salário, esta parece ser a melhor representante dos efeitos encadeadores para frente, que fortalecem os efeitos das forças centrípetas de aumentos populacionais. Nas regressões para populações urbanas e rurais, essa variável mostrou-se de grande importância, especialmente no caso do crescimento da população urbana, para a qual o coeficiente da variável Salário é 49,7\% maior que no caso 
da regressão para o crescimento da população rural. Esse é mais um resultado que reitera a superação das forças centrípetas em relação às centrífugas.

Grande parte dos efeitos das mudanças populacionais observadas e discutidas acima pode ser atribuída às mudanças nos custos de transportes. O Índice de Acessibilidade, também chamado de potencial de mercado - variável $P M$ (Acessibilidade) nas Tabelas 1 e 2 - capta esse efeito e vários outros, todos em consonância com os pressupostos da NGE. Na avaliação das mudanças populacionais nas zonas rurais, o Índice de Acessibilidade surtiu efeitos negativos, implicando que sua melhoria em $1 \%$ diminui a taxa de crescimento da população rural em $0,75 \%$. É a variável de maior impacto na regressão para explicar o crescimento da população rural. Na regressão para explicar o crescimento da população urbana, seu efeito é positivo, o qual pressupõe aumento de $0,20 \%$ na taxa de crescimento da população urbana para cada melhoria de $1 \%$ no índice. Nota-se, portanto, que esse indicador pode explicar movimentos de pessoas, assim como a localização das firmas (como discutido por Head e Mayer, 2004). O forte efeito do Índice de Acessibilidade sobre o crescimento da população rural e urbana está relacionado aos seguintes fatores: a) proximidade aos maiores centros urbanos; b) redução dos custos de transportes; c) acesso a mercados e a bens e serviços.

Melhor acessibilidade representa mais facilidade de acesso à oferta de negócios e serviços de alta ordem, como shopping centers, por exemplo. As cidades mais próximas tendem a ter taxa de crescimento superior, uma vez que passam a ser mais atrativas do ponto de vista econômico e social. As cidades mais distantes tendem a perder população ou crescer a taxas muito inferiores. A partir de então, as pessoas das zonas rurais migram para as cidades, seja essas grandes, seja apenas próximas às aglomerações. De fato, o coeficiente positivo do Índice de Acessibilidade pa- ra o crescimento da população urbana e negativo para a população rural, juntamente com a variável que capta os efeitos de proximidade às grandes aglomerações (grandes cidades da Região Norte), sugere que esse fenômeno está ocorrendo naquela região.

Os coeficientes da Tabela 2 indicam haver supremacia das forças centrípetas, ou de atração, em relação às forças centrífugas no crescimento da população urbana. Quando isso ocorre, tem-se a formação de um modelo centro-periferia, fundamentado pela NGE. Os efeitos encadeados para frente são notáveis, com forte atração da população rural em direção às zonas urbanas, assim como efeitos encadeados para trás, atraindo grandes empresas para a Região Norte.É uma combinação de resultados que oferecem evidências às hipóteses formuladas neste trabalho, de que as principais cidades da Região Norte estão atuando como "indutores do crescimento". Entretanto, essa força motriz se restringe àquelas cidades localizadas no entorno dos maiores centros urbanos. Tal assertiva sugere que as cidades mais distantes carecem de políticas públicas específicas, no sentido de evitar o declínio de sua população, que tende a migrar para as grandes cidades.

Como consequência do exposto, pode-se cometer o erro de investir grandes quantias nas maiores cidades em detrimento das cidades mais distantes. Se isso ocorrer, tão somente se está contribuindo para fortalecer ainda mais o modelo centro-periferia. Por conseguinte, as políticas públicas direcionadas às cidades com mais baixo Índice de Acessibilidade, para serem mais efetivas, devem ser aplicadas isoladamente, isto é, em cada município. A consolidação de um modelo centro-periferia, tal como o que está ocorrendo na Região Norte, é prejudicial ao seu desenvolvimento econômico. Sua extensa área geográfica, os baixos Índices de Acessibilidade e as questões ambientais inerentes dificultam o processo de difusão das riquezas concen- 
tradas nas maiores cidades, ou seja, sua força de spillovers é reduzida. Possivelmente, são essas as razões que levam a tamanha desigualdade socioeconômica existente na Região Norte. $\mathrm{O}$ baixo nível de acessibilidade parece ser 0 gargalo do isolamento das cidades do Norte, tornando as forças centrípetas cada vez mais fortes.

\section{5_Conclusões}

A Região Norte do Brasil apresenta acentuada heterogeneidade, que compreende desde cidades praticamente isoladas a modernos centros urbanos e indicadores socioeconômicos do melhor ao pior do Brasil. Diante desse contexto, o objetivo deste artigo foi analisar o crescimento populacional dessa região, entre 1980 e 2000, à luz das argumentações da Nova Geografia Econômica (NGE), que se dedica a estudar, entre outros aspectos, os processos de formação de aglomerações (como a de pessoas). Os resultados sugeriram que grande parte da desigualdade de crescimento populacional dentro da Região Norte é causada, entre outros fatores, pelas dificuldades de acesso. Desse modo, a compreensão do processo aglomerativo dessa região, por meio do qual se supôs que as maiores cidades estão atuando como "indutores de crescimento", é essencial. Essas formulações proveem instrumentos que auxiliam os tomadores de decisão no direcionamento de políticas públicas de melhoria da qualidade de vida.

O Índice de Acessibilidade mostrou-se como importante elemento para explicar o crescimento desigual dos municípios da Região Norte. Os municípios mais distantes apresentaram os mais baixos índices, e, justamente nessas áreas, foram identificados também os piores indicadores econômicos e sociais, como demonstra a literatura. De modo geral, houve aumento da acessibilidade, suficiente para estimular a migração intensa das zonas rurais para as urbanas, mas não o suficiente para estimular a produção e aumentar a renda nesses locais. Não obstante, resultados esclarecedores foram obtidos nas regressões estimadas.

Os resultados econométricos produziram evidências que confirmam as hipóteses formuladas. Em primeiro lugar, os municípios mais pobres têm no fator isolamento geográfico um dos determinantes da sua condição econômica. As dificuldades de acesso impedem esses municípios de escoar sua produção, que, na maioria dos casos, é agropecuária, aos mercados potenciais. Em segundo, houve redução nos custos de transportes, que culminou na melhoria da acessibilidade, formando as aglomerações populacionais. As forças centrípetas superaram as forças centrífugas, formando um modelo centro-periferia. Consequentemente, as grandes aglomerações passaram a demandar produtos da própria região, gerando crescimento e melhorando as condições socioeconômicas de seus vizinhos, portanto, atuando como "indutores de crescimento". Todavia, esses efeitos de difusão de externalidades positivas apresentaram-se muito reduzidos, implicando que políticas públicas direcionadas aos grandes centros não seriam as mais adequadas.

De acordo com os resultados encontrados, para melhorar a acessibilidade das cidades mais isoladas e a consequente melhoria das condições de vida de sua população, seriam necessários investimentos isolados, isto é, em cada município. Entretanto, esse tipo de política é dispendiosa. Deste modo, uma alternativa plausível de aumento da acessibilidade seriam investimentos em pontos centrais da Região Norte, de tal forma que o tempo de viagem da cidade mais isolada a uma cidade de maior porte pudesse ser reduzido substancialmente. Como exemplo, a construção de um hospital dotado de completa infraestrutura no município de Tefé, que fica a 49 horas de Manaus, poderia reduzir o tempo de viagem de Atalaia do Norte (a cidade mais isolada, distante de Manaus por 104 horas de viagem) pela me- 
tade, além de beneficiar toda a população no alto do Rio Solimões. Ademais, o município de Tefé está mais próximo de Coari, que cresce graças à exploração do gás natural.

Considerando que a demanda por produtos agrícolas por parte das maiores cidades pode crescer, possivelmente investimentos em polos regionais como Coari e Tefé poderiam atuar como "indutores do crescimento", aumentando a acessibilidade daquelas cidades que ficaram isoladas. Além disso, estimular a produção local das potencialidades econômicas sustentáveis de cada município diminui também os efeitos das forças centrífugas. Para tanto, deveriam ser feitos investimentos em infraestrutura de transporte, de modo que o escoamento da produção agrícola fosse facilitado. Esse é um ponto importante, uma vez que, apesar da intensa mudança da população rural para urbana, a zona rural ainda tem poder de atração via salários, dado o coeficiente positivo dessa variável no modelo econométrico. Adicionalmente, caberiam as alternativas de aumentar o mercado potencial para a Região Norte.

A primeira solução seria criar os subpolos regionais, onde os governos investiriam em infraestrutura de modo que facilitassem o escoamento e o deslocamento da produção das cidades vizinhas. A solução complementar é o aumento do mercado potencial via expansão das fronteiras. As ligações comerciais deveriam ser intensificadas junto aos países vizinhos como Colômbia e Equador, que estão mais próximos das cidades mais isoladas da Região Norte. A Venezuela, as Guianas e o Suriname têm ligação direta com os Estados de Roraima, Amazonas, Amapá e Pará. Estes dois últimos têm ligação direta com o Oceano Atlântico, o qual viabilizaria o transporte da produção da economia, via o porto de Belém, por exemplo, para a Europa. Além desses países, a Região Norte tem ainda a vantagem de estar mais próxima do maior mercado consumidor do mundo, os Estados Unidos. Havendo essa expansão das fronteiras comerciais, seu mercado potencial não ficaria tão limitado ao mercado de São Paulo, por exemplo. Enfim, esses são alguns exemplos de políticas que podem ser pensadas com base nos resultados aqui apresentados.

\section{Notas}

${ }^{1}$ A Região Norte abrange área total de 3,9 milhões de quilômetros quadrados, a qual equivale a cerca de $42,3 \%$ do território brasileiro e está integralmente contida no bioma amazônico. Portanto, ao referir-se à Amazônia, refere-se, implicitamente, à Região Norte do Brasil, que é composta de sete Estados, divididos em 449 municípios (situação em 2000).

${ }^{2}$ No ano de 2000, o pior IDH foi registrado para o município de Manari, no Estado do Pernambuco. A média brasileira foi de 0,76 , e o melhor IDH do Norte foi o de Belém, com 0,806.

${ }^{3}$ Em que $\sigma$ é a elasticidade preço da demanda para cada variedade disponível. Ressaltando que se trata de uma função CES (Constant Elasticity Substitution).

${ }^{4}$ Apesar dos problemas envolvendo a equação de potencial de mercado, alguns trabalhos testando seus argumentos já foram realizados. Entre eles: Puga e Venables (1996), Ottaviano e Pinelli (2006) e, aplicado ao Brasil, Silveira Neto (2005).
${ }^{5} \mathrm{O}$ cálculo de $W_{j R}$ segue a mesma formulação dos índices para os municípios da Região Norte.

${ }^{6}$ Não foi diferenciado o transporte de carga do transporte de passageiros, já que na Amazônia é mais comum o uso de um mesmo barco para transportar pessoas (no convés) e cargas (no porão).

${ }^{7}$ Belém, Conceição do Araguaia, Ji Paraná, Macapá, Manaus, Porto Velho, Rio Branco e Santarém.

${ }^{8}$ Quando $\Delta x$ é pequeno, a diferença entre o logaritmo de $\mathrm{x}+\Delta \mathrm{x}$ e o logaritmo de $\mathrm{x}$ é aproximadamente $\Delta \mathrm{x} / \mathrm{x}$, isto é, $(\ln x+\Delta x)-\ln (\mathrm{x}) \cong \Delta \mathrm{x} / \mathrm{x}$. Assim, o uso do logaritmo permite interpretar os resultados de maneira direta, isto é, uma mudança percentual na variável independente está associada a uma mudança percentual na variável dependente (Stock; Watson, 2006).

${ }^{9}$ Essas cidades, não necessariamente, eram capitais em 1980 (ver a nota de rodapé número 7). 
${ }^{10}$ Os subscritos $i$ e $j$ são utilizados na literatura, por convenção, para distinguir uma região $i$ de outra j. Portanto, no cálculo do Índice de Acessibilidade, foi utilizado o mesmo $j$ para identificar o mercado a ser atingido a partir de $i$.

${ }^{11}$ A distribuição dos erros é normal, com média zero, variância constante, independentes e identicamente distribuídos.

${ }^{12}$ Em 1980, existiam 205 municípios. Esses foram desmembrados e geraram mais 244, totalizando 449 no ano de 2000. Pelo método acima, a base de comparação são 205 AMC. Isso implica agregar os dados de 2000 para as 205 AMC.

${ }^{13}$ No período das cheias, as correntezas dos rios se intensificam. Ao mesmo tempo, a viagem se torna mais difícil em razão das grandes toras de madeiras que são arrancadas das margens, dificultando, sobremaneira, a navegação. 
ADES, A. F.; GLAESER, Ed. L. Trade and circuses: explaining urban giants. The Quarterly Journal of Economics,

Cambridge, v. 110, n. 1, p. 195-227, Jan. 1995.

AMARAL, P. V.; LEMOS, M. B.; SIMÕES, R. F.; FERES, F. C Regional imbalances and market potential in Brazil. Belo Horizonte: UFMG/CEDEPLAR, 2007. 24 p. (Texto para Discussão 324).

ANDERSEN, L. C.; GRANGER, C. W. J.; REIS, J. E.; WEINHOLD, D.; WUNDER, S. The dynamics of deforestation and economic growth in the Brazilian Amazon. Cambridge: Cambridge University Press, 2002. $395 \mathrm{p}$.

\section{ANSELIN, L. Spatial} econometrics: Methods and models. Boston: Kluwer Academic, 1988, 304 p.

BEHRENS, K.; THISSE J. F. Regional economics: A new economic geography perspective. Regional Science and Urban Economics,

Maryland, v. 37, n. 4, p. 457-465, July 2007.
DA MATA, D.; DEICHMANN, U.; HENDERSON, J. V.; LALL, S. V.; WANG, H.G. Examining the growth patterns of Brazilian cities. Washington: World Bank, 2005. (Policy Research Working Paper 3724).

DA SILVA, Renilson R. Pobreza no Estado do Amazonas: Uma análise espacial. In: ENABER, 7., 2009, São Paulo. Anais.. São Paulo, 2009.

DA SILVA, Renilson R. Aglomerações populacionais na Região Norte do Brasil de 1980 a 2000: Uma análise por meio da Nova Geografia Econômica. 2011, 147 p. Tese (Doutorado em Economia Aplicada), Universidade de São Paulo, Piracicaba, 2011.

DA SILVA, Renilson R.; BACHA, C. J. C. Polígonos de Voronoi como alternativa aos problemas das áreas mínimas comparáveis: Uma análise das mudanças populacionais na Região Norte no Brasil. Revista Brasileira de Estudos de População, São Paulo, v. 28, n. 1, p. 133-151, 2011.

FLORAX, R. J. G. M.; FOLMER, H.; REY, S. J. Specification searches in spatial econometrics: The relevance of Hendry's methodology. Regional Science and Urban Economics, Maryland, v. 33, n. 5, p. 557-579, 2003.
FUJITA, M.; KRUGMAN, P.; VENABLES, A. J. Economia espacial. Urbanização, prosperidade econômica e desenvolvimento humano no mundo. São Paulo: Futura, 2002. $384 \mathrm{p}$.

GALLUP, J. L.; SACHS, J. D.; MELLINGER, A. D. Geography and economic development. International Regional Science Review. Tempe, v. 22, n. 2, p. 179-232, 1999.

GLAESER, E. L.; SCHEINKMAN, J. A.; SHLEIFE, A. Economic growth in a cross-section of cities. Journal of Monetary Economics, Maryland, v. 36, n. 2, p. 117-143, 1995.

\section{HARRIS C. The market as a} factor in the location of industry in the United States. Annals of the Association of American Geographers, New York, v. 44, p. 315-48, 1954

\section{HEAD, K.; MAYER, T. The} empirics of agglomeration and trade. In: HENDERSON, V.; THISSE, J. F. (Ed.). Handbook of urban and regional economics. Amsterdam: Elsevier, 2004. chap. 9, 2609-2665.

KRUGMAN, P. Geography and trade. Cambridge, US: MIT Press, 1991. 156 p.
MORENO, R.; VAYÁ, E. Técnicas econométricas para el tratamiento de datos espaciales: La econometría espacial. Investigaciones regionales. Universidad de Barcelona, Barcelona, p. 83-106, 2000.

NEARY, J. P. Of hype and hyperbolas: Introducing the new economic geography. Journal of Economic Literature, Pittsburgh, v. 39, p. 536-561, 2001.

O'KELLY, M. E.; HORNER, M. W. Aggregate accessibility to population at the county level: U.S. 1940-2000. Journal of Geographic Systems, New York, v. 5, 5-23 p., Jan., 2003.

OTTAVIANO, G.; PINELLI,

D. Market potential and productivity: Evidence from finnish regions. Regional Science and Urban Economics, Maryland, v. 36, n. 5, p. 636-657, Sept. 2006.

PAEZ, A. Network accessibility and the spatial distribution. Urban Studies, London, v. 41, n. 1, p. 2211-2230, Oct. 2004.

PARTRIDGE, M.; OLFERT, M. R.; ALASIA, A. Canadian cities as regional engines of growth: Agglomeration and amenities. Canadian Journal of

Economics, Montreal, v. 40, n. 1, Feb. 2007. 
PRATES, R. C.; BACHA, C. J. C. Os processos de desenvolvimento e desmatamento da Amazônia. Economia e Sociedade,

Campinas, v. 20, p. 3-43, 2011.

PUGA, D.; VENABLES, A. J. The spread of industry: Spatial agglomeration in economic development. Centre for Economic Performance.

Discussion Paper No. 279, Feb. 1996.

REIS, E. J.; PIMENTEL, M.;

ALVARENGA, A. I. Áreas

mínimas comparáveis para os

períodos intercensitários de

1872 a 2000. Mimeo, IPEA/DIMAC, Rio de Janeiro 2008.

REDDING, S.; VENABLES, T.

Economic geography and

international inequality,

\section{Journal of International}

Economics, New York, v. 62, p. 53-82, Jan. 2004.

SILVEIRA NETO, R. M.

Concentração industrial regional, especialização geográfica e geografia econômica: Evidências para o Brasil no período 19502000. Revista Econômica do Nordeste, Fortaleza, v. 36, n. 2, p. 189-208, 2005.

STOCK, J. H.; WATSON, M. W. Introduction to econometrics. $2^{\text {nd }}$ Edition. New York:

Pearson, 2006. $840 \mathrm{p}$.

WONG, L. R. (Org.). $O$ envelhecimento da população brasileira e o aumento da E-mail de contato dos autores: renilsonsilva@uol.com.br carlosbacha@usp.br longevidade - Subsídios para políticas orientadas ao bemestar do idoso. Belo Horizonte: UFMG/CEDEPLAR, 2001. 
Tabela A.1_Diagnóstico de dependência espacial nas estimativas do crescimento das populações rural e urbana

\begin{tabular}{|c|c|c|c|c|}
\hline & Teste & MI/DF & Valor & Probabilidade \\
\hline \multirow{6}{*}{$\begin{array}{l}\text { População } \\
\text { rural }\end{array}$} & Moran's I (error) & 0,169 & 4,488 & $0,000 \% * *$ \\
\hline & Lagrange Multiplier (error) & 1,000 & 13,985 & 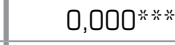 \\
\hline & Robust LM (error] & 1,000 & 1,605 & $0,205^{* * * *}$ \\
\hline & Lagrange Multiplier (lag) & 1,000 & 20,216 & 0,000 兼前 \\
\hline & Robust LM (lag) & 1,000 & 7,836 & $0,005^{* * * *}$ \\
\hline & Lagrange Multiplier (SARMA) & 2,000 & 21,820 & 0,000 米米范 \\
\hline \multirow{6}{*}{$\begin{array}{l}\text { População } \\
\text { urbana }\end{array}$} & Moran's I (error) & 0,105 & 3,014 & 0,000 **** \\
\hline & Lagrange Multiplier (error] & 1,000 & 5,478 & $0,001^{\text {前米并 }}$ \\
\hline & Robust LM (error] & 1,000 & 0,933 & 0,334000 \\
\hline & Lagrange Multiplier (lag) & 1,000 & 8,918 & 0,000 *前* \\
\hline & Robust LM (lag) & 1,000 & 4,373 & 0,037 * \\
\hline & Lagrange Multiplier (SARMA) & 2,000 & 9,850 & 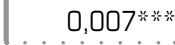 \\
\hline
\end{tabular}

Fonte: Elaborada com base nos dados da pesquisa e do programa SpaceStat.

Notas: ${ }^{* *}$ significativo a $1 \%$; ${ }^{* \star}$ significativo a $5 \%$; ${ }^{\star}$ significativo a $10 \%$.

Tabela A.2_Estimação da equação (5) para o crescimento da população rural com defasagem espacial e apenas com variáveis estatisticamente significativas

\begin{tabular}{|c|c|c|c|c|}
\hline Variável & Coeficiente & $\begin{array}{l}\text { Erro } \\
\text { padrão }\end{array}$ & $z$ valor & Probabilidade \\
\hline Rho & 0,252 & 0,048 & 5,219 & 0,0 羊前 \\
\hline Intercepto & 0,558 & 0,088 & 6,351 & 0,0 前前 \\
\hline \% Pop urb. Emprego & $-0,238$ & 0,043 & $-5,571$ & 0,0 些前 \\
\hline \% Pop rur. Emprego & 0,490 & 0,038 & 12,824 & 0,0 些前 \\
\hline IDH-Renda & 0,199 & 0,087 & 2,282 & $0,0 \%$ \\
\hline IDH-Educação & $-0,350$ & 0,182 & $-1,926$ & $0,022 \%$ \\
\hline IDH-Longevidade & $-0,325$ & 0,059 & $-5,465$ & $0,054 \%$ \\
\hline Salário Rural & 0,422 & 0,030 & 14,198 & 0,0 \%** \\
\hline PM (Acessibilidade) & $-0,669$ & 0,112 & $-5,963$ & 0,0 前前 \\
\hline Interação & 0,567 & 0,072 & 7,926 & 0,0 前前 \\
\hline
\end{tabular}

Fonte: Elaborada com base nos dados da pesquisa e do programa SpaceStat. Notas: ${ }^{* *}$ significativo a $1 \%$; ${ }^{* *}$ significativo a $5 \%$; ${ }^{*}$ significativo a $10 \%$.
Tabela A.3_Estimação da equação (7) para o crescimento da população urbana com erro espacial e apenas com variáveis explicativas estatisticamente significativas

\begin{tabular}{|c|c|c|c|c|c|}
\hline Variável & Coeficiente & $\begin{array}{l}\text { Erro } \\
\text { padrão }\end{array}$ & z valor & \multicolumn{2}{|c|}{ Probabilidade } \\
\hline Lambda & 0,325 & 0,092 & 3,544 & 0,000 & *\%* \\
\hline Intercepto & 0,047 & 0,087 & 0,541 & 0,589 & \\
\hline Latitude & 0,045 & 0,023 & 1,915 & 0,055 & \\
\hline Prox. Capitais & 0,070 & 0,043 & 1,601 & 0,109 & \\
\hline \%Pop urb. Emprego & 0,153 & 0,042 & 3,653 & 0,000 & *关羊 \\
\hline \%Pop rur. Emprego & $-0,052$ & 0,031 & $-1,647$ & 0,099 & \\
\hline IDH-Educação & 0,162 & 0,093 & 1,743 & 0,081 & \\
\hline IDH-Longevidade & $-0,281$ & 0,180 & $-1,557$ & 0,119 & \\
\hline IDH-Renda & $-0,418$ & 0,060 & $-6,988$ & 0,000 & $* *$ \\
\hline Salário Urbano & 0,641 & 0,030 & 21,502 & 0,000 & H \\
\hline PM (Acessibilid & 0,192 & 0,056 & 3,428 & 0,001 & ** \\
\hline
\end{tabular}

Fonte: Elaborada com base nos dados da pesquisa e do programa SpaceStat. Notas: ${ }^{* *}$ significativo a $1 \%$; ${ }^{* *}$ significativo a $5 \%$; ${ }^{*}$ significativo a $10 \%$. 